\title{
COMPARATIVE CHARACTERISTICS OF ECONOMY'S SOCIAL ATTRIBUTES OF THE SYSTEM LEVELS OF HIERARCHY FROM THE STANDPOINT OF ECONOMIC AND MATHEMATICAL MODELING ${ }^{1}$
}

\author{
Mikhail Yu. Kussy \\ V.I. Vernadsky Crimean Federal University, Simferopol, Russian Federation \\ Oleg L. Korolyov \\ V.I. Vernadsky Crimean Federal University, Simferopol, Russian Federation
}

\begin{abstract}
As a result of the research, the paper shows the essential need to take into account the social attributes of processes and phenomena in economy. From the standpoint of the interdisciplinary approach at various levels of the system three-hierarchy (micro-meso-macro) in economy, the following characteristics of social attributes are considered: "economic agent", "expectations of the economic agent" and "preferences of the economic agent" taking into account their heteromorphism and heterogeneity, "intersubjective relations in economy", "trust" between economic agents, "institutions". The conclusions made as a result of the study make it possible to formulate the concept of selecting tools for economic and mathematical modeling of processes and phenomena at various levels of the system three-hierarchy (micro-meso-macro) in economy. Further studies will make it possible to select the most relevant tools for each level of the system three-hierarchy from the numerous apparatus used to model processes and phenomena in economy taking into account the concept proposed in this paper.
\end{abstract}

Key words: three-hierarchy (micro-meso-macro) in economy, economic agent, expectations of the economic agent, preferences of the economic agent, intersubjective relations in economy, trust, institutions.

Citation. Kussy M.Yu., Korolyov O.L. Comparative Characteristics of Economy’s Social Attributes of the System Levels of Hierarchy from the Standpoint of Economic and Mathematical Modeling. Journal of Volgograd State University. Economics, 2019, vol. 21, no. 4, pp. 22-35. (in Russian). DOI: https://doi.org/10.15688/ ek.jvolsu.2019.4.3

\section{СРАВНИТЕЛЬНАЯ ХАРАКТЕРИСТИКА СОЦИАЛЬНЫХ АТРИБУТОВ СИСТЕМНЫХ УРОВНЕЙ ИЕРАРХИИ В ЭКОНОМИКЕ С ПОЗИЦИЙ ЭКОНОМИКО-МАТЕМАТИЧЕСКОГО МОДЕЛИРОВАНИЯ ${ }^{1}$ \\ Михаил Юрьевич Куссый}

Крымский федеральный университет им. В.И. Вернадского, г. Симферополь, Российская Федерация

\section{Олег Леонидович Королев}

Крымский федеральный университет им. В.И. Вернадского, г. Симферополь, Российская Федерация

Аннотация. В результате проведенных исследований в статье показана существенная необходимость учета социальных атрибутов процессов и явлений в экономике. С позиций междисциплинарного подхода на различных уровнях системной триерархии (микро-мезо-макро) в экономике рассмотрены характеристики следующих социальных атрибутов: «экономический агент»; «ожидания экономического агента» и «предпочтения экономического агента» с учетом их гетероморфности и гетерогенности; «межсубъектные отно- 
шения в экономике»; «доверие», складывающееся между экономическими агентами; «институты». Сделанные в результате проведенного исследования выводы позволили сформулировать концепцию отбора инструментария для экономико-математического моделирования процессов и явлений на различных уровнях системной триерархии (микро-мезо-макро) в экономике. Дальнейшие исследования позволят отобрать из имеющегося многочисленного аппарата, применяющегося при моделировании процессов и явлений в экономике, наиболее релевантные инструменты для каждого уровня системной триерархии с учетом предложенной в работе концепции.

Ключевые слова: триерархия (микро-мезо-макро) в экономике, экономический агент, ожидания экономического агента, предпочтения экономического агента, межсубъектные отношения в экономике, доверие, институты.

Цитирование. Куссый М. Ю., Королев О. Л. Сравнительная характеристика социальных атрибутов системных уровней иерархии в экономике с позиций экономико-математического моделирования // Вестник Волгоградского государственного университета. Экономика. - 2019. - Т. 21, № 4. - C. 22-35. - DOI: https://doi.org/10.15688/ek.jvolsu.2019.4.3

\section{Введение}

Концептуальные основы современной экономической науки и математический аппарат, который она использует, почти полностью сформированы в первой половине XX века. Однако глобализация финансовых рынков, усиление интеграции национальных экономик, ускорение научно-технического прогресса, сокращение жизненного цикла товаров и технологий, сложные рефлексивные процессы в экономике - все это приводит к необходимости переосмысления существующего научного экономического наследия и разработке новых методологических и эпистемологических парадигм, соответствующих требованиям достижений актуальной науки и практики. Целью такого переосмысления, по мнению В.Д. Базилевича и В.В. Ильина, которое они изложили в работе «Метафизика экономики», является достижение следующего условия: «Современное теоретико-экономическое знание должно давать более целостное понимание явлений и процессов в экономике, отображением которых это знание является» [Базилевич и др., 2007, с. 16].

Необходимость использования междисциплинарного подхода в экономических исследованиях отмечена, например, в [von Furstenberg, 1990; Автономов, 2006; Ерзнкян, 2010]. Правда, ответов на вопросы о том, как применять междисциплинарный подход в экономических исследованиях и достижения каких научных дисциплин следует учитывать в таких исследованиях, авторы не предлагают.
Среди современного инструментария в экономике следует выделить поведенческую экономику, которая приобретает все большую популярность в исследовании экономических явлений и процессов. Это происходит потому, что этот подход позволяет взглянуть на объект исследования с позиции, отличающейся от позиций экономико-теоретического мейнстрима середины XX в., и разъяснить некоторые аспекты экономической действительности, которые были недоступны для релевантного понимания с позиций экономико-теоретического мейнстрима середины XX века. Вопросы, касающиеся объяснительного потенциала поведенческой экономики с использованием психологического подхода, разбираются в [Camerer et al., 2004].

Проблемы таксономии и стратификации в экономике также до сих пор не имеют однозначного разрешения, что «определяет необходимость переосмысления современных тенденций эволюции глобализирующейся хозяйственной системы для выработки новой, логически и методологически непротиворечивой иерархической модели структуризации экономического пространства» [Фролов, 2013].

Необходимость включения в системную иерархическую структуру экономики промежуточного уровня для разрешения существующих эпистемологических и методологических проблем бинарности дихотомии микро- / макро- отмечена в значительном количестве исследований (см., например: [Ng, 1986; Holland, 1987; Ozawa, 1999; Dopfer et al., 2004; Elsner, 2007; Фролов, 2013; Дерябина, 2018]). 
Несмотря на существующую неоднозначность подходов к смысловому наполнению категории «мезоуровень в экономике» (см., например: [Dopfer et al., 2004; Elsner, 2007; Дерябина, 2018; Маевский, 2017]) - эпистемологическое и методологическое значение внедрения этого понятия в анализ экономических явлений и процессов трудно переоценить. Так, в [Haken, 1988] мезоуровень выделен «в качестве необходимого для описания <и понимания $>2$ природы субординации уровней развития от микроскопического мира к макроскопическому». Методологический смысл выделения мезоуровня в системной иерархии экономики заключается в том, что именно на этом уровне происходит формирование и трансформация структур как важной системной характеристики. И именно поэтому, как отмечал Г. Хакен, «во многих случаях систему вообще достаточно анализировать на мезоуровне, так как формируемые на этом уровне структуры уже содержат необходимую информацию об эволюции системы и ее самоорганизации» [Haken, 1988]. На мезоуровне происходит «колоссальное сжатие информации $<$ формирование и трансформация структурных атрибутов мезоуровня на основе структурных атрибутов микроуровня $>\ldots$ отбирается и сохраняется только та, которая имеет реальное и решающее значение для формирования социальноэкономических структур» [Дерябина, 2018].

Включение в бинарную системную иерархию в экономике мезоуровня и исследования на междисциплинарном уровне социальных атрибутов получившейся триерархии позволяют по-новому взглянуть на механизмы разрешения некоторых проблем современной экономической науки.

\section{Авторские замечания по смысловой нагрузке некоторых терминов, используемых в работе}

С целью конкретизации смыслового содержания терминов, используемых в статье. Отметим некоторые особенности их интерпретации в нашей работе.

Социальное правило - обязательный для выполнения механизм, предписывающий «в ситуации X делать Ү... сюда включаются как нормы поведения и социальные конвенции, так и юридические и формальные правила» [Ходжсон, 2003, с. 11].

Институт - социальное правило, имеющее определенный актуальный набор атрибутов. Более четкая конкретизация категории «институт», неоднозначность трактовки которой отмечена, например, в [Voigt, 2013], остается вне рамок статьи.

Актуальная институциональная система в экономике (далее - АИС) - это текущий набор действующих институтов (пусть не всегда зафиксированных в нормах действующего законодательства), используемых (пусть даже ситуативно) в общественно значимой практике межсубъектных отношений в экономике (далее - МСОЭ).

Жизненный цикл института (далее ЖЦИ) - временной интервал, в течение которого институт является актуальным для применения в практике МСОЭ.

Основным элементом экономики считаем экономического агента (далее - ЭА; такой подход вполне согласуется с взглядами на роль ЭА, определенную в [Giddens, 1984; Kussy et al., 2019]), который не только активно воздействует на социально-экономические процессы, но и сам является непосредственным участником этих процессов. ЭА - лицо, выполняющее одну или несколько социально-экономических функций в рамках МСОЭ. Последнее определение не претендует на законченность; подробнее проблемы категоризации этого термина рассмотрены в [Giddens, 1984; Луман, 2006].

Система индивидуальных парадигм (далее - СИП) ЭА - субъективный набор индивидуально категоризированных объектов, субъектов, процессов и причинно-следственных связей между ними, который на основании личного опыта ЭА приобретает характер субъективных «знаний» (включая усвоенные общественно значимые опыт и знания, вписывающиеся в личную систему парадигм).

С помощью СИП ЭА субъективно-ситуативно интерпретирует объекты, субъекты и процессы внешнего мира, как это отмечено в [Балацкий, 2011]. Она же (СИП) активно воздействует на процессы формирования и закрепления (на уровне индивидуальных нормправил) у ЭА привычек, склонностей, стерео- 
типов действий и механизмов мышления и т. п. Экономические агенты в каком-то смысле сами «“создают" <при помощи СИП> ту реальность, в которой действуют» [Hayek, 1952].

Подход с использованием СИП для понимания эпистемологии процессов принятия ЭА решений вполне согласуется с концепцией феномена «Verstehen», подробно обсуждаемой в [Блауг, 2004, с. 98-104], согласно которой «общественные науки должны основываться на знании от первого лица, доступному каждому человеческому существу, а не на знании от третьего лица, полученному с помощью измерения результатов экспериментов». Именно наличие «Verstehen» отличает общественные науки от естественных, в которых наблюдатель, как правило, не является участником процессов (в русском языке термин «Verstehen» можно заменить конструкцией «мне ясно, что...»).

Поведение ЭА по отношению к текущему состоянию конкретного экономического процесса определяется его текущими ожиданиями (что в том числе отмечено в [Балацкий, 2011; Куссый, 2019а]): индивидуальное понимание конкретным ЭА альтернативных возможностей будущей эволюции анализируемого экономического процесса как результата разнообразных эндогенных и экзогенных воздействий на него; в том числе и со стороны ЭА. Каждый ЭА имеет свои текущие предпочтения: индивидуальные взгляды на желаемое направление - с позиций ЭА - будущей эволюции конкретного экономического процесса.

Современная экономика, включая почти все процессы, происходящие в ней, - результат разнонаправленных и различных по силе воздействий на процессы принятия решений (далее - гетероморфность) ожиданий и предпочтений разных ЭА, имеющих разнообразную природу происхождения (далее - гетерогенность), нашедших свое агрегированное итоговое отражение в МСОЭ между ЭА. Гетерогенность и гетероморфность у ЭА обсуждается, например, в [Vittikh, 2015b; Куссый, 2019a].

Актуальные ожидания и предпочтения ЭА формируют цели и мотивы последних на вступление в МСОЭ для достижения целей каждым ЭА. При этом мотивы ЭА зачастую являются в том числе движителями разработки (в рамках MCOЭ) новых технологий и иных инноваций (в рамках ограничений, формируемых АИС, а также существующих технологических и ресурсных ограничений). В этом смысле МСОЭ могут более динамично видоизменяться и трансформироваться, чем АИС, которая обладает некоторой инерционностью (об инерционности институтов в экономике см., например: [Журавский, 2006]).

Устойчивое экономическое сообщество (далее - УЭС) - это совокупность ЭА, обладающая признаками, отмеченными в [Ильясов, 2016]: регулярное взаимодействие; групповая самоидентификация; идентификация сообщества внешними по отношению к сообществу агентами; общность целей взаимодействия; сообщество являет собой единый субъект действия.

УЭС существуют внутри технологических укладов и создают часть общественного продукта. Эмпирическое значение УЭС в формировании МСОЭ и эволюции экономики нашло отражение, например, в [Маевский, 2017, Кирдина и др., 2015].

В литературе УЭС имеют различные наименования: «холоны» [Vittikh, 2015a], «рои» [Ostrom, 1990], «макрогенерации», или популяции экономических подсистем [Маевский, 2017], «субсети» [Freeman et al., 1988] и другие.

Ввиду ограниченности объема публикации результатов исследования - не будем пытаться в статье полностью определить такие непростые категории, как уровни экономической иерархии, что уже составляло предмет различных исследований (см., например: [Dopfer et al., 2004; Elsner, 2007; Фролов, 2013; Дерябина, 2018]), которые показали значительные трудности, возникающие при решении этой проблемы.

\section{Роль экономических агентов}

\section{на различных уровнях триерархии}

Французский социолог П. Бурдье разработал концепцию габитуса (habitus), согласно которой следует разделять в социуме понятия «субъект», «агент», «актор» [Bourdieu, 1980]: «Агент в определенном смысле действует сам < микроуровень>, в отличие от 
субъекта... <на мезоуровне>, который лишь актуализирует правила < институты>». П. Бурдье вводит термин «агент» вместо «актора» (который обычно используется в социологии), чтобы подчеркнуть способность индивида действовать свободно. «Актор» предполагает, напротив, наличие детерминизма, определяемого АИС, которому подчинен агент, функционирующий в социуме на макроуровне.

Действие агента (согласно концепции П. Бурдье) «фактически есть продукт "бессознательных стратегий” <базирующихся на СИП>, которые он реализовывает. Стратегии действий сформированы из оснований (диспозиций), усвоенных агентом с учетом специфики его субъективной системы парадигм $<$ СИП агента $>$, разрешающей или препятствующей использованию вновь поступающей информации» в процессе принятия социально-экономических решений и определяющей механизмы такого использования. Совокупность таких диспозиций составляет габитус (СИП агента).

Для наглядности наиболее существенные характеристики категории «экономический агент» на разных уровнях системной триерархии в экономике представлены в таблице 1.
Роль ожиданий и предпочтений экономических агентов на различных уровнях триерархии в экономике

На микроуровне в качестве ЭА выступает, как правило, индивид или представитель (руководитель) малого или среднего бизнеса. Здесь гетероморфность и гетерогенность текущих ожиданий и предпочтений ЭА является одной из существенных причин повышения уровня неопределенности в развитии любого экономического процесса [Куссый, 2019а], сопровождающегося ситуативным формированием МСОЭ.

Как отметил М.Ю. Барбашин, на мезоуровне «институциональная гомогенность понижает естественную склонность индивидов к оппортунизму рациональным ожиданием получения отдачи от долговременных “инвестиций” <в УЭС > . Но, как только институциональное пространство перестает быть гомогенным, имплицитные контрактные обязательства у членов сообщества по сохранению институтов культуры, языка, социализации и проч. фактически разрушаются. "Засорение”

Таблица 1

Характеристика категории «экономический агент» на разных уровнях системной триерархии в экономике

\begin{tabular}{|c|c|c|}
\hline Микроуровень & Мезоуровень & Макроуровень \\
\hline $\begin{array}{l}\text { Агент-индивид с широким спектром } \\
\text { индивидуальных социально-психо- } \\
\text { логических характеристик и особен- } \\
\text { ностей и большим количеством сте- } \\
\text { пеней социальной свободы, которое } \\
\text { определяется в значительной степе- } \\
\text { ни системой индивидуальных пара- } \\
\text { дигм (СИП) ЭА }\end{array}$ & $\begin{array}{l}\text { Агент-актор, который уже выступа- } \\
\text { ет не только как индивид, но и как } \\
\text { член УЭС, что неизбежно приводит } \\
\text { к снижению его количества степе- } \\
\text { ней социальной свободы, которое } \\
\text { определяется в значительной степе- } \\
\text { ни СИП УЭС }\end{array}$ & $\begin{array}{l}\text { Агент-субъект (здесь уже ЭА как } \\
\text { типичная социальная единица уров- } \\
\text { ня иерархии - не индивид, а УЭС), } \\
\text { количество степеней социальной } \\
\text { свободы которого детерминируется } \\
\text { в значительной степени АИС }\end{array}$ \\
\hline
\end{tabular}

Примечания:

1. В рамках проводимого исследования не рассматривается дифференциация ЭА по его принадлежности к той или иной организационной форме, отрасли и т. п.

2. Подробнее о механизмах, влияющих на количество степеней социальной свободы см., например, в [Луман, 2006, с. 14-19].

3. Что касается экономической свободы ЭА, то она (в самом общем случае) детерминируется актуальными ограничениями институционального, технологического и ресурсного характера. При этом с повышением уровня триерахии от микроуровня к макроуровню ограничения институционального характера сокращают экономическую свободу в связи с интеграцией ЭА в УЭС на мезоуровне и в общество - в самом широком смысле этого слова - на макроуровне. А в работе [Луман, 2006] утверждается, что любая интеграция ЭА приводит к сокращению количества степеней его свободы. Ограничения технологического и ресурсного характера с повышением уровня триерахии от микроуровня к макроуровню повышают количество степеней экономической свободы ЭА. Это связано, опять же, с его интеграцией в объединения ЭА и ростом, обусловленным этой интеграцией, его ресурсными и технологическими возможностями. 
монолитного институционального пространства другими паттернами поведения усложняет идентификационный выбор и заставляет социальных субъектов селекционировать институциональные практики» [Барбашин, 2014].

Мезоуровень позволяет (благодаря доминированию на этом уровне триерахии УЭС в качестве типичной единицы социально-экономического пространства) агрегировать и актуализировать совокупность гетероморфных и гетерогенных текущих ожиданий и предпочтений ЭА, формируемых, в том числе, на микроуровне.

Именно мезоуровень «сглаживает» хаотичность ситуативных социально-экономических процессов, происходящих на микроуровне, снижая уровень неопределенности в МСОЭ. На мезоуровне спектр девиантности и оппортунизма в МСОЭ по отношению к актуальной институциональной системе существенно ограничен процессами институциональной кооперации ЭА в УЭС.

На макроуровне значение текущих индивидуальных ожиданий и предпочтений ЭА жестко ограничивается и практически нивелируется АИС: здесь спектр девиантности и оппортунизма ЭА в МСОЭ по отношению к АИС практически сведен к нулю. Но именно на макроуровне фиксируются и закрепляются в институтах нормы, ранее считавшиеся девиантными и прошедшие апробацию на релевантность и социальную значимость на мезоуровне. Механизмы внедрения норм, ранее считавшиеся девиантными в АИС, описываются в [Барбашин, 2014].

Для наглядности наиболее существенные характеристики категории «гетероморфность и гетерогенность текущих ожиданий и предпочтений экономических агентов» на разных уровнях системной триерархии в экономике представлены в таблице 2.

\section{Сравнительная характеристика механизмов организации межсубъектных отношений \\ на различных уровнях триерархии}

\section{в экономике}

Процессам формирования типа МСОЭ на микроуровне присущи индивидуальная ситуативность [Barbashin, 2017], нарративность [Вольчик и др., 2018] и зачастую уникальность. Это приводит к высокому уровню неопределенности в МСОЭ, который снижается внедрением в МСОЭ категории «доверие» (подробней об этой категории см., например, в [Королев, 2019]).

Мезоуровнень следует считать полигоном для ревизии норм АИС в практике МСОЭ, где происходит апробация целесообразности и общественной значимости вновь генерируемых и выявление неэффективно действующих институтов (с учетом текущих ожиданий и предпочтений агентов).

Для наглядности наиболее существенные характеристики категории «межсубъектные отношения в экономике» на разных уровнях системной триерархии представлены в таблице 3.

\section{Характеристика процессов функционирования и трансформации институциональной системы на различных уровнях триерархии}

Следует отметить, что на всех уровнях триерархии при формировании МСЭО представлены в той или иной мере институты со

Таблица 2

\section{Характеристика категории «гетероморфность и гетерогенность текущих ожиданий и предпочтений экономических агентов» на разных уровнях системной триерархии в экономике}

\begin{tabular}{|l|l|l|}
\hline \multicolumn{1}{|c|}{ Микроуровень } & \multicolumn{1}{|c|}{ Мезоуровень } & \multicolumn{1}{|c|}{ Макроуровень } \\
\hline $\begin{array}{l}\text { Представлена широким спектром } \\
\text { ожиданий и предпочтений ЭА }\end{array}$ & $\begin{array}{l}\text { Ограниченная (здесь текущие ожи- } \\
\text { дания и предпочтения ЭА агрегиру- }\end{array}$ & $\begin{array}{l}\text { Значение текущих индивидуальных } \\
\text { ожаний и предпочтений ЭА соз- } \\
\text { ются и актуализируются в рамках } \\
\text { нательно ими (ЭА) жестко ограни- } \\
\text { чИВается и практически нивелирует- } \\
\end{array}$ \\
& $\begin{array}{l}\text { конфлде сглаживаются возможные } \\
\text { морфностью и гетерогенностью) }\end{array}$ & $\begin{array}{l}\text { ся под детерминированными воз- } \\
\text { действиями АИС }\end{array}$ \\
\hline
\end{tabular}

Примечание. Составлено авторами. 


\section{Характеристика категории «межсубъектные отношения в экономике» на разных уровнях системной триерархии}

\begin{tabular}{|c|c|c|}
\hline Микроуровень & Мезоуровень & Макроуровень \\
\hline $\begin{array}{l}\text { Характерный здесь тип МСОЭ фор- } \\
\text { мируется с учетом индивидуальной } \\
\text { ситуативности и зачастую уникаль- } \\
\text { ности процессов такого формирова- } \\
\text { ния, что приводит к высокому уров- } \\
\text { ню дифференциации и повышению } \\
\text { уровня неопределенности в МСОЭ. } \\
\text { Последний может быть снижен пу- } \\
\text { тем ситуативно-кооперативного и } \\
\text { солидарного внедрения в МСОЭ ка- } \\
\text { тегории «доверие». При этом дове- } \\
\text { рие на микроуровне зиждется лишь } \\
\text { на ситуативно-субъективных ожида- } \\
\text { ниях и предпочтениях ЭА в рамках } \\
\text { СИПЭА, участвующих в МСОЭ. } \\
\text { Здесь характерен высокий уровень } \\
\text { девиантности и оппортунизма в } \\
\text { МСОЭ по отношению к АИС }\end{array}$ & $\begin{array}{l}\text { На мезоуровне величина девиантно- } \\
\text { сти и оппортунизма в МСОЭ по от- } \\
\text { ношению к АИС ограничена процес- } \\
\text { сами институциональной коопера- } \\
\text { ции ЭА в УЭС. МСОЭ здесь прису- } \\
\text { щи избирательная, сознательная } \\
\text { коллективность (определяемая спе- } \\
\text { цификой солидарных формирования } \\
\text { и эволюции конкретного УЭС) и } \\
\text { склонность к компромиссам в рам- } \\
\text { ках коллаборации и коммуникатив- } \\
\text { ной координации агентов в УЭС, что } \\
\text { существенно ограничивает неопре- } \\
\text { деленность в МСОЭ по сравнению с } \\
\text { микроуровнем. } \\
\text { Доверие на мезоуровне детермини- } \\
\text { руется механизмами формирования } \\
\text { и функционирования УЭС с учетом } \\
\text { СИП УЭС }\end{array}$ & $\begin{array}{l}\text { Формой организации МСОЭ здесь } \\
\text { является конвенция (в основном - } \\
\text { между УЭС), где каждый ее член } \\
\text { знает не только о правилах поведе- } \\
\text { ния, но и о том, что у других есть } \\
\text { такое же знание о правилах. Такие } \\
\text { конвенции, в основном, базируются } \\
\text { на нормах АИС. При этом уровень } \\
\text { неопределенности в МСОЭ снижа- } \\
\text { ется за счет уже не только интегра- } \\
\text { ции ЭА в УЭС, но и в значительной } \\
\text { степени ограничивается АИС, спо- } \\
\text { собствуя эволюции процессов соли- } \\
\text { дарной самоорганизации и унифика- } \\
\text { ции МСОЭ на макроуровне, что од- } \\
\text { новременно повышает уровень кон- } \\
\text { серватизма в МСОЭ на макроуровне } \\
\text { в противовес девиантности и оппор- } \\
\text { тунизму, присущим микроуровню. } \\
\text { На макроуровне механизмы доверия } \\
\text { между ЭА в МСОЭ заменяются кон- } \\
\text { венционально-институциональными } \\
\text { механизмами уровня }\end{array}$ \\
\hline
\end{tabular}

Примечания:

1. В рамках проводимого исследования не рассматривается дифференциация МСОЭ по отраслевому (или иному функциональному) признаку, по их принадлежности к малому, среднему, крупному бизнесу.

2. Предполагается, что отношения доверия в разрезе триерархии носят ассиметричный характер. Принцип определения уровня триерархии заключается в том, кто определяет доверие. Так, отношения доверия индивида будут определяться на микроуровне как к другим индивидам, так и к группам (сообществам) и обществу (обществам) в целом. Доверие группы (УЭС) формируется на мезоуровне и определяется обобщенной целью или идеей формирования самой группы, с одной стороны, и внешней репрезентацией уровня компетенции - с другой.

3. Основной формой организации МСОЭ на макроуровне является «конвенция... это в основном термин для перцепции части игроков группы о том, как должны играть остальные» [Miller, 1990]. Такие конвенции базируются в основном на нормах АИС.

всех трех уровней. В рамках текущего исследования будем рассматривать для каждого уровня триерархии лишь институты, отражающие типовые особенности формирования и функционирования МСОЭ на этом уровне.

Микроуровень следует рассматривать в качестве полигона для апробации широкого спектра институциональных новаций (включая девиантные, оппортунистические и даже деструктивные идеи институционального характера по формированию нового или трансформации уже существующего института). При этом обоюдный контроль соблюдения норм таких институтов и институциональных новаций, как правило, возлагается на участников сделки.
Типичные причины неисполнения институтов на микроуровне системной экономической иерархии рассмотрены О.С. Сухаревым [Сухарев, 2011].

Здесь особенно актуальной становится возможность институциональных новаций в рамках конкретной сделки, если ее предметом является некая инновация, механизмы внедрения и совместной эксплуатации которой пока не имеют институционального закрепления. Поэтому уровень неопределенности в МСОЭ в таком случае чрезвычайно велик (см. обсуждение вероятных последствий внедрения в повсеместную практику блокчейн-технологий в [Kussy et al., 2018]). При этом основная направленность (или мотив) 
необходимости формирования новых и трансформации существующих институтов АИС снижение уровня текущей ситуативной неопределенности в МСОЭ.

Согласно авторской точке зрения микроуровень следует считать полигоном для ревизии релевантности существующих институтов и генерации новых, определяющих механизмы формирования МСОЭ, ввиду индивидуализма, присущего агентам, которые функционируют на этом уровне системной иерархии. Здесь присутствуют разнообразные проявления девиантности и оппортунизма в МСОЭ по отношению к АИС [Барбашин, 2018], нарративные трактовки норм действующих институтов [Barbashin, 2017]. Именно поэтому микроуровень является «возмутителем спокойствия» процессов (в том числе институционального характера), протекающих на макроуровне, где эти процессы носят агрегированный характер и достаточно жестко детерминируются существующими институциональными, технологическими, ресурсными и иными ограничениями.
Как отмечено в [Барбашин, 2014] эволюционная трансформация институтов на мезоуровне связана с упрощением их норм. В этом смысле конвенционализация ЭА в УЭС на мезоуровне способствует внедрению таких социальных норм, которые снижают уровень социальной неопределенности в МСОЭ. К тому же конвенционализация снижает транзакционные издержки ввиду присутствия в УЭС процессов коллаборационной кооперации ЭА.

Снижая уровень социальной непредсказуемости МСОЭ, конвенциональные «институциональные правила обеспечивают нас информацией об ожидаемых действиях других, и в этом отношении ограничивают наш выбор. ... < Институты являются $>$ способностью находить надежный способ по оказанию воздействия на ожидания других... и принуждать других действовать противоположно их неограниченным предпочтениям» [Knight, 1992].

Для наглядности наиболее существенные характеристики категории «институт» на разных уровнях системной триерархии представлены в таблице 4.

Таблииа 4

\section{Характеристика категории «институт» на разных уровнях системной триерархии}

\begin{tabular}{|c|c|c|}
\hline Микроуровень & Мезоуровень & Макроуровень \\
\hline $\begin{array}{l}\text { Микроинституты имеют характер } \\
\text { индивидуальных договоренностей } \\
\text { в рамках конкретной сделки ЭА } \\
\text { (здесь институты, как правило,-- } \\
\text { единичные нормы, в общем случае } \\
\text { не признаваемые социумом как } \\
\text { общественно значимые), направ- } \\
\text { ленных на снижение уровня неоп- } \\
\text { ределенности в МСОЭ. Период } \\
\text { ЖЦИ микроинститута, как прави- } \\
\text { ло, определяется сроком действия } \\
\text { конкретной сделки. Трансакцион- } \\
\text { ные издержки могут быть сниже- } \\
\text { ны за счет внедрения в МСОЭ ка- } \\
\text { тегории «доверие» }\end{array}$ & $\begin{array}{l}\text { Мезоинституты имеют характер } \\
\text { конвенций в рамках кооперации } \\
\text { ЭА в УЭС (социально значимые } \\
\text { правила, направленные на сниже- } \\
\text { ние уровня неопределенности в } \\
\text { МСЭО внутри УЭС). Трансакци- } \\
\text { онные издержки, оплачиваемые, } \\
\text { как правило, ЭА в УЭС вскладчи- } \\
\text { ну, - минимальны. При этом мо- } \\
\text { ниторинг и контроль соблюдения } \\
\text { норм мезоинститутов организован } \\
\text { в рамках УЭС. Длина ЖЦИ во } \\
\text { времени у мезоинститутов соизме- } \\
\text { рима со сроком актуальности су- } \\
\text { ществования УЭС, которое вне- } \\
\text { дрило этот институт в практику } \\
\text { МСОЭ }\end{array}$ & $\begin{array}{l}\text { Здесь подавляющее большинство } \\
\text { институциональных норм уже } \\
\text { имеет признание как релевантных } \\
\text { и социально значимых, апробиро- } \\
\text { ванных в практике МСОЭ на мезо- } \\
\text { уровне. Механизмы контроля со- } \\
\text { блюдения агентами норм институ- } \\
\text { та здесь определены, как правило, } \\
\text { на общественно-государственном } \\
\text { уровне (в том числе и на уровне } \\
\text { саморегулируемых организаций по } \\
\text { профессиональным видам дея- } \\
\text { тельности). При этом трансакци- } \\
\text { онные издержки, как правило, су- } \\
\text { щественно возрастают: размер } \\
\text { транзакционных издержек в де- } \\
\text { нежном эквиваленте на этом уров- } \\
\text { не, как правило, закреплен в нор- } \\
\text { мативных документах }\end{array}$ \\
\hline
\end{tabular}

Примечания:

1. Подробнее про трансакционные издержки см., например, в [Попов, 2011].

2. По мнению Уго Пагано: «Появление новых институтов напоминает возникновение новых биологических видов: оно требует комбинации большого количества эволюционных изменений и ресурсов <на различных уровнях триерархии> ... институты трансформируются, модифицируются, редактируются, транслируются и соединяются с другими нормами и правилами их носителей, которые пытаются диагностировать, интерпретировать и предложить различные решения существующих проблем, создавая новый смысл и новые значимые образцы социального поведения в различных ситуациях» [Pagano, 1991]. 


\section{ЭКОНОМИЧЕСКАЯ ТЕОРИЯ}

\section{Концепция использования \\ существенных характеристик \\ социальных атрибутов триерархии \\ в экономико-математическом моделировании}

При экономико-математическом моделировании, как правило, не учитываются социальные атрибуты экономических явлений и процессов, ввиду неоднозначности механизмов их формализации. В рамках текущего исследования для решения этой проблемы предлагается концепция отбора математического инструментария при моделировании экономических явлений и процессов с учетом полученных выше результатов.

С эпистемологической точки зрения при построении экономико-математических моделей для стохастичных процессов в социально-экономических системах (далее СЭС) авторами рекомендуется использовать инструментарий дифференциального исчисления (из онтологии математики дифференциал - инструмент, у которого системная память во времени стремится к нулю: $\frac{d y}{d t}=\lim _{\Delta t \rightarrow 0} \frac{y\left(t_{i}\right)-y\left(t_{i-\Delta t}\right)}{\Delta t} ;$ о системной памяти экономических процессов см., например, в [Куссый, 2019б]). Что же касается процессов в СЭС, где доминирует детерминизм, для них рекомендуется использовать интегральный инструментарий (из онтологии математики интеграл - инструмент, у которого системная память во времени стремится к бесконечности: $\int_{T 1}^{T 2} y(t) d t=\lim _{\Delta t \rightarrow 0} \sum_{i=0}^{N} y\left(t_{i}\right) \Delta t_{i}$, где $\left.N \rightarrow \infty\right)$. Хотя для сложных СЭС с большим количеством элементов и разнообразных связей между ними, видимо, следует прибегать к тензорным операторам, включающим как дифференциалы, так и интегралы (в том числе дробного порядка, что обсуждается в [Tarasov et. al., 2017]). Целесообразность использования тензорных операторов при моделировании процессов в СЭС с учетом системной памяти и МСОЭ, которое, в том числе, предложено в [Шишкин, 2017], объясняется следующим: математический оператор в таком случае отображение из пространства количественных значений характеристик процесса в простран- ство принятия решений в экономике. Тензорный тип оператора выбран потому, что, как правило, процессы в экономике описываются многозначными зависимостями с помощью модели матричного типа (для статического случая матричное представление элементов СЭС и их взаимосвязей используется, в том числе, в [Шишкин, 2017; Клевец, 2018]), которое (представление модели) преобразуется в динамике вдоль вектора времени во временной ряд таких матриц.

Учитывая полученные выше результаты, процессы, происходящие на микроуровне триерархии, ввиду субъективно-ситуативного поведения их социальных атрибутов, следует скорее отнести к классу стохастичных. Это, в свою очередь, приводит к необходимости преобладания в используемом при моделировании математического аппарата - инструментария дифференциального типа.

Процессы, происходящие на макроуровне триерархии, ввиду агрегированного поведения их социальных атрибутов, следует скорее отнести к классу детерминированных. Это, в свою очередь, приводит к необходимости преобладания в использовании инструментария интегрального типа при моделировании экономических явлений и процессов на этом уровне триерархии.

Что же касается мезоуровня триерархии, то рекомендуемый здесь инструментарий моделирования достаточно подробно рассмотрен в [Kruglova et al., 2019].

Хотя в любом случае, при математическом моделировании явлений и процессов, проходящих на различных уровнях системной триерархии в экономике, следует придерживаться двенадцати правил, описанных в [Куссый, 2019a].

\section{Заключение}

Использование триерархической системы в экономике позволяет с новой точки зрения рассмотреть некоторые проблемы экономики России и дает дополнительный методологический инструмент для поиска возможного решения этих проблем.

Как показано в работе, микро- и мезоуровни иерархии и процессы формирования МСОЭ на них имеют существенное значение 
для эволюционных процессов в экономике и трансформации АИС. Именно поэтому в России требуется осуществить комплекс мероприятий по увеличению доли среднего и малого бизнеса в экономике страны с целью оздоровления действующей системы институций.

Введение мезоуровня в иерархию уровней экономики может позволить разрешить методологические проблемы дихотомий: микро- / макро- и методологический индивидуализм / методологический холизм, а также их динамические аспекты, связанные с этими дихотомиями (пока большинство теоретических достижений в экономике, увы, носят статический характер).

Следует отметить, что на каждом уровне триерархии могут иметь место все три описанных типа институциональных норм и МСОЭ. Выше выделены лишь доминирующие типы институтов и МСОЭ на соответствующем уровне иерархии.

Возможно, что для более детальных исследований процессов, происходящих в экономике России, потребуется расширить количество уровней иерархии, как это предложено, например, в [Иншаков, 2004].

Представленная здесь концепция использования существенных характеристик социальных атрибутов триерархии в экономико-математическом моделировании позволит - с эпистемологической точки зрения - системно подходить к выбору релевантного инструментария при моделировании экономических явлений и процессов.

Дальнейшие исследования позволят отобрать из имеющегося многочисленного аппарата, применяющегося при моделировании процессов и явлений в экономике, наиболее релевантные инструменты для каждого уровня системной триерархии с учетом предложенной в работе концепции.

Представленная работа носит постановочный, проблемный характер, направлена на развертывание научной дискуссии и предполагает дальнейшие исследования и апробацию результатов исследований по заявленной тематике.

\section{ПРИМЕЧАНИЯ}

${ }^{1}$ Исследование выполнено при финансовой поддержке РФФИ в рамках научного проекта № 19-010-00298.
The reported study was funded by RFBR in the framework of research project no. 19-010-00298.

2 Здесь и далее примечания автора даны в угловых скобках.

\section{СПИСОК ЛИТЕРАТУРЫ}

Автономов, В. С. Методологические проблемы современной экономической науки / В. С. Автономов // Вестник российской академии наук. - 2006. - Т. 76, № 3. - С. 203-208.

Базилевич, В. Д. Метафизика экономики / В. Д. Базилевич, В. В. Ильин. - Киев : Знання, 2007. $718 \mathrm{c}$.

Балацкий, Е. В. Когнитивно-институциональный синтез Д. Норта / Е. В. Балацкий // Общественные науки и современность. - 2011. - № 5. C. $154-166$.

Барбашин, М. Ю. Институты и идентичность: методологические возможности теории институционального распада в современных социальных исследованиях / М. Ю. Барбашин // Журнал социологии и социальной антропологии. - 2014. - Т. 17, № 4. - С. 178-188.

Барбашин, М. Ю. Социальные свойства институтов / М. Ю. Барбашин // Социологические исследования. -2018. - № 2. - С. 25-34.

Блауг, М. Методология экономической науки, или Как экономисты объясняют / М. Блауг. - М. : Вопросы экономики, 2004. - 416 с.

Вольчик, В. В. Нарративы, идеи и институты / В. В. Вольчик, Е. В. Маслюкова // Terra economicus. 2018. - T. 16, №2. - C. 150-168. - DOI: 10.23683/ 2073-6606-2018-16-2-150-168.

Дерябина, М. А. Методологические основания исследования мезоуровня экономики как сложной системы / М. А. Дерябина // Journal of institutional studies (Журнал институциональных исследований). -2018. - Т. 10, № 3. -С. 30-39.DOI: 10.17835/2076-6297.2018.10.3.030-039.

Ерзнкян, Б. А. Включение социальных факторов в индивидуальные предпочтения: возможности и перспективы / Б. А. Ерзнкян // Экономическая наука современной России. - 2010. № 1 (48). - С. 21-40.

Журавский, М. Ю. О воздействии экономического времени на инвестиционные интересы / М. Ю. Журавский // Вестник Томского государственного университета. - 2006. - № 292. C. 322-327.

Ильясов, Ф. Н. Группа и групповое поведение / Ф. Н. Ильясов // Социальные исследования. -2016 . - № 1. - С. 1-20.

Иншаков, О. В. Уровневый анализ объекта, предмета и метода экономической теории / О. В. Ин- 
шаков // Известия Санкт-Петербургского университета экономики и финансов. - 2004. № 4. - C. 5-19.

Кирдина, С. Г. Климат и институциональные матрицы / С. Г. Кирдина, А. Н. Кузнецова, О. В. Сенько // СОЦИС. - 2015. - № 9. -С. 3-13.

Клевец, Н. И. Сравнительный анализ методов многокритериального ранжирования альтернатив / Н. И. Клевец // Научный вестник: Финансы, банки, инвестиции. - 2018. - № 2. - С. 153-163.

Королев, О. Л. Влияние цифровизации на трансформацию социально-экономических отношений / О. Л. Королев // Системный анализ и информационные технологии (САИТ-2019) : труды конференции. - М. : ФИЦ ИУ РАН, 2019. C. $456-460$.

Куссый, М. Ю. Гносеологические аспекты процессов самоорганизации в социально-экономических системах с позиций экономико-математического моделирования : монография / М. Ю. Куссый.-М. : ИНФРА-М, 2019а. - 178 с.

Куссый, М. Ю. Про память в социально-экономических системах / М. Ю. Куссый // Системный анализ и информационные технологии (САИТ-2019) : труды конференции.-М. : ФИЦ ИУ РАН, 2019б. - С. 430-439.

Луман, Н. Дифференциация / Н. Луман. - М. : Логос, 2006. $-320 \mathrm{c}$.

Маевский, В. И. Эволюционная теория, макрогенерации и неравновесные процессы / В. И. Маевский // Очерки по экономической синергетике. - М. : ИЭ РАН, 2017. - С. 31-45.

Попов, Е. В. Трансакционность экономических институтов развития / Е. В. Попов // Вестник УрФУ. Серия: Экономика и управление. 2011. - № 4. - С. 4-14.

Сухарев, О. С. Экономика будущего: теория институциональных изменений (новый эволюционный подход) / О. С. Сухарев. - М. : Финансы и статистика, 2011.-432 с.

Фролов, Д. П. Многоуровневая иерархия экономического пространства: формирование эволюционной таксономии / Д. П. Фролов // Пространственная экономика. - 2013. - № 4. C. 122-150. - DOI: https://doi.org/10.14530/ se.2013.4.122-150.

Ходжсон, Дж. Экономическая теория и институты: Манифест современной институциональной экономической теории / Дж. Ходжсон. - М. : Дело, 2003. - 464 c.

Шишкин, В. В. Обеспечение антирецессионного развития российского предпринимательства : дис. ... д-ра экон. наук : 08.00.05 / Шишкин Виктор Викторович. - СПб., 2017. - 431 с.

Barbashin, M. Y. Imitation Modeling and Institutional Studies / M. Y. Barbashin // Journal of Institutional
Studies. - 2017. - Vol. 9, no. 3. - P. 81-96. DOI: https://doi.org/10.17835/2076-6297.2017. 9.3.081-096.

Blockchain Technologies as a Stimulator of Institutional Transformations of the World Financial System / M. Yu. Kussy [et al.] // International Journal of Engineering and Technology (UAE). - 2018. - Vol. 7, no. 3.14: Special Issue 14. - P. 354-359. - DOI: https:// doi.org/10.14419/ijet.v7i3.14.17025.

Bourdieu, P. Le sens pratique / P. Bourdieu. - Paris : Minuit, 1980. $-479 \mathrm{p}$.

Camerer, C. F. Behavioral Economics: Past, Present, Future / C. F. Camerer, G. Loewenstein ; C. F. Camerer, G. Loewenstein, \& M. Rabin (Eds.) // Advances in Behavioral Economics. - Princeton : Princeton University Press, 2004. - P. 3-51.

Dopfer, K. Micro-Meso-Macro / K. Dopfer, J. Foster, J. Potts // Journal of Evolutionary Economics. 2004. - Vol. 14, no 3. - P. 263-279. - DOI: https:// doi.org/10.1007/s00191-004-0193-0.

Elsner, W. Why Meso? On "Aggregation" and "Emergence", and Why and How the Meso Level is Essential in Social Economics / W. Elsner // Forum for Social Economics. - 2007. - Vol. 36, no. 1. - P. 1-16. - DOI: https://doi.org/10.1007/ s12143-007-0001-3.

Freeman, C. Structural Crises of Adjustment: Business Cycles and Investment Behaviour / C. Freeman, C. Perez; Dosi G. [et al.] (eds.) // Technical Change and Economic Theory. - London ; N.Y. : Pinter Publishers, 1988. - P. 38-66.

Furstenberg, G. M. von. Acting Under Uncertainty : Multidisciplinary Conceptions / G. M. von Furstenberg. - Bloomington : Springer-Science + Business Media, B. V., 1990. - 532 p.

Giddens, A. The Constitution of Society. Outline of the Theory of Structuration / A. Giddens. Cambridge : Polity Press ; Oxford : Basil Blackwell, 1984. -402 p. + XXXVII.

Haken, H. Information and Self Organization: a Macroscopic Approach to Complex Systems / H. Haken. - Berlin ; N.Y. : Springer-Verlag, 1988. $-196 \mathrm{p}$.

Hayek, F. A. The Sensory Order: an Inquiry into the Foundations of Theoretical Psychology / F. A. Hayek. - Chicago : University of Chicago Press, 1999. - 232 p. - DOI: https://doi.org/ 10.7208/chicago/9780226321301.001.0001.

Holland, S. The Market Economy. From Micro to Mesoeconomics / S. Holland. - L. : Weidenfeld and Nicholson, 1987. $-370 \mathrm{p}$.

Knight, J. Institutions and Social Conflict / J. Knight. Cambridge : Cambridge University Press, 1992.234 + XIII p. - DOI: https://doi.org/10.1017/ CBO9780511528170. 
Kruglova, M. S. Meso-Level of Economy: Theoretical Approaches and Math Modeling / M. S. Kruglova, A. I. Volynskii, I. L. Kirilyuk // Journal of Institutional Studies. - 2019. - Vol. 11, no. 1. P. 41-54. - DOI: https://doi.org/10.17835/20766297.2019.11.1.041-054.

Miller, G. M. Managerial Dilemmas: Political Leadership in Hierarchies / G. M. Miller ; K. Cook, M. Levi (eds.) // The Limits of Rationality. - Chicago : University of Chicago Press, 1990. - P. 343-344.

$\mathrm{Ng}$, Yew-Kwang. Mesoeconomics. A Micro-Macro Analysis / Yew-Kwang Ng. - Brighton : WheatsheafBooks, 1986. - 267 p. - DOI: https:// doi.org/10.2307/ 2233193 .

Ostrom, E. Governing the Commons: the Evolution of Institutions for Collective Action / E. Ostrom. Cambridge : Cambridge University Press, 1990.$280 \mathrm{p}$.

Ozawa, T. Organizational Efficiency and Structural Change: a Meso-Level Analysis / T. Ozawa // Structural Change and Cooperation in the Global Economy / G. Boyd, H.J. Dunning (eds.). Cheltenham ; Northampton : Edward Elgar, 1999. - P. 160-190.

Pagano, U. Property Rights, Asset Specificity and the Division of Labor Under Alternative Capitalist Relations / U. Pagano // Cambridge Journal of Economics. - 1991. - Vol. 15, № 3.P. 315-342.

Tarasov, V. Economic Growth Model With Constant Pace and Dynamic Memory / V. Tarasov, V. Tarasova // Entropy. - 2017. - № 2 (84). P. 40-45. - DOI: https://doi.org/10.20861/23042338-2017-84-001.

Vittikh, V. A. Introduction to the Theory of Intersubjective Management/V. A. Vittikh// Group Decision and Negotiation. - 2015a. - Vol. 24, iss. 1.-P. 67-95.DOI: https://doi.org/10.1007/s10726-014-9380-z.

Vittikh, V. A. Heterogeneous Actor and Everyday Life as Key Concepts of Evergetics / V. A. Vittikh // Group Decision and Negotiation. - 2015b. Vol. 24, iss. 6. - P. 949-956. - DOI: https://doi.org/ 10.1007/s10726-014-9423-5.

Voigt, S. How (Not) to Measure Institutions / S. Voigt // Journal of Institutional Economics. - 2013. № 9. - P. 1-26. - DOI: https://doi.org/10.1017/ S1744137412000148.

\section{REFERENCES}

Avtonomov V.S. Metodologicheskie problemy sovremennoy ekonomicheskoy nauki [Methodological Problems of Modern Economic Science]. Vestnik rossiyskoy akademii nauk [Herald of the Russian Academy of Sciences], 2006, vol. 76, no. 3, pp. 203-208.
Bazilevich V.D., Ilyin V.V. Metafizika ekonomiki [Metaphysics of Economics]. Kiev, Znannya, 2007. 718 p. (in Ukrainian).

Balatsky E.V. Kognitivno-institutsionalnyy sintez D. Norta [Cognitive-Institutional Synthesis of D. North]. Obshchestvennye nauki i sovremennost [Social Sciences and Contemporary World], 2011, no. 5, pp. 154-166.

Barbashin M.Yu. Instituty i identichnost: metodologicheskie vozmozhnosti teorii institutsionalnogo raspada $\mathrm{v}$ sovremennykh sotsialnykh issledovaniyakh [Institutions and Identity: Methodological Possibilities of the Theory of Institutional Decay in Modern Social Research]. Zhurnal sotsiologii i sotsialnoy antropologii [The Journal of Sociology and Social Anthropology], 2014, vol. 17, no. 4, pp. 178-188.

Barbashin M.Yu. Sotsialnye svoystva institutov [Social Properties of Institutes]. Sotsiologicheskie issledovaniya [Sociological Studies], 2018, no. 2, pp. 25-34.

Blaug M. Metodologiya ekonomicheskoy nauki, ili Kak ekonomisty obyasnyayut [Methodology of Economic Science, or How Economists Explain]. Moscow, Voprosy ekonomiki Publ., 2004. 416 p.

Volchik V.V., Maslyukova E.V. Narrativy, idei i instituty [Narratives, Ideas and Institutions]. Terra economicus, 2018, vol. 16, no. 2, pp. 150-168. DOI: 10.23683/2073-6606-2018-16-2-150-168.

Deryabina M.A. Metodologicheskie osnovaniya issledovaniya mezourovnya ekonomiki kak slozhnoy sistemy [Methodological Foundations of the Study of the Mesoscale of the Economy as a Complex System]. Journal of institutional studies, 2018, vol. 10, no. 3, pp. 30-39. DOI: 10.17835/2076-6297.2018.10.3.030-039.

Erznkyan B.A. Vklyuchenie sotsialnykh faktorov v individualnye predpochteniya: vozmozhnosti i perspektivy [Inclusion of Social Factors in Individual Preferences: Opportunities and Prospects]. Ekonomicheskaya nauka sovremennoy Rossii [Economics of Contemporary Russia], 2010, no. 1 (48), pp. 21-40.

Zhuravsky M.Yu. O vozdeystvii ekonomicheskogo vremeni na investitsionnye interesy [On the Impact of Economic Time on Investment Interests]. Vestnik Tomskogo gosudarstvennogo universiteta [Tomsk State University Journal], 2006, no. 292, pp. 322-327.

Ilyasov F.N. Gruppa i gruppovoe povedenie [Group and Group Behavior]. Sotsialnye issledovaniya [Journal of Social Research], 2016, no. 1, pp. 1-20.

Inshakov O.V. Urovnevyy analiz obyekta, predmeta i metoda ekonomicheskoy teorii [Level Analysis of the Object, Subject and Method of Economic Theory]. Izvestiya Sankt-Peterburgskogo universiteta ekonomiki $i$ finansov [Izvestiâ 
Sankt-Peterburgskogo gosudarstvennogo èkonomičeskogo universiteta], 2004, no. 4, pp. 5-19.

Kirdina S.G., Kuznetsova A.N., Senko O.V. Klimat i institutsionalnye matritsy [Climate and Institutional Matrices]. SOTSIS [Socis], 2015, no. 9 , pp. 3-13.

Klevets N.I. Sravnitelnyy analiz metodov mnogokriterialnogo ranzhirovaniya alternativ [Comparative Analysis of the Methods of MultiCriteria Ranking of Alternatives]. Nauchnyy vestnik: Finansy, banki, investitsii [Scientific Bulletin: Finance, Banking, Investment], 2018, no. 2, pp. 153-163.

Korolev O.L. Vliyanie tsifrovizatsii na transformatsiyu sotsialno-ekonomicheskikh otnosheniy [Influence of Digitalization on the Transformation of Socio-Economic Relations]. Sistemnyy analiz i informatsionnye tekhnologii (SAIT-2019): trudy konferentsii [System Analysis and Information Technologies (SAIT 2019). Conference Proceedings]. Moscow, FITS IURAN, 2019, pp. 456-460.

Kussy M.Yu. Gnoseologicheskie aspekty protsessov samoorganizatsii v sotsialno-ekonomicheskikh sistemakh s pozitsiy ekonomikomatematicheskogo modelirovaniya: monografiya [Epistemological Aspects of SelfOrganization Processes in Socio-Economic Systems from the Standpoint of Economic and Mathematical Modeling. Monograph]. Moscow, INFRA-M Publ., 2019a. 178 p.

Kussy M.Yu. Pro pamyat v sotsialno-ekonomicheskikh sistemakh [About Memory in Socio-Economic Systems]. Sistemnyy analiz i informatsionnye tekhnologii (SAIT-2019): trudy konferentsii [System Analysis and Information Technologies (SAIT - 2019). Conference Proceedings]. Moscow, FITS IU RAN, 2019b, pp. 430-439.

Luman N. Differentsiatsiya [Differentiation]. Moscow, Logos Publ., 2006. 320 p.

Maevsky V.I. Evolyutsionnaya teoriya, makrogeneratsii i neravnovesnye protsessy [Evolutionary Theory, Macrogeneration and Nonequilibrium Processes]. Ocherki po ekonomicheskoy sinergetike [Essays on Economic Synergetics]. Moscow, IE RAN, 2017, pp. 31-45.

Popov E.V. Transaktsionnost ekonomicheskikh institutov razvitiya [Transactional Economic Development Institutions]. Vestnik UrFU. Seriya: Ekonomika i upravlenie [Bulletin of Ural Federal University. Series Economics and Management], 2011, no.4, pp. 4-14.

Sukharev O.S. Ekonomika budushchego: teoriya institutsionalnykh izmeneniy (novyy evolyutsionnyy podkhod) [Economics of the
Future: Theory of Institutional Change (New Evolutionary Approach)]. Moscow, Finansy i statistika Publ., 2011. 432 p.

Frolov D.P. Mnogourovnevaya ierarkhiya ekonomicheskogo prostranstva: formirovanie evolyutsionnoy taksonomii [Multilevel Hierarchy of Economic Space: The Formation of Evolutionary Taxonomy]. Prostranstvennaya ekonomika [Spatial Economics], 2013, no. 4, pp. 122-150. DOI: 10.14530/se.2013.4.122-150.

Hodgson J. Ekonomicheskaya teoriya i instituty: Manifest sovremennoy institutsionalnoy ekonomicheskoy teorii [Economic Theory and Institutions: Manifesto of Modern Institutional Economic Theory]. Moscow, DeloPubl., 2003. 464 p.

Shishkin V.V. Obespechenie antiretsessionnogo razvitiya rossiyskogo predprinimatelstva: dis. ... d-ra ekon. nauk [Ensuring the Antirecessionary Development of Russian Entrepreneurship. Dr. econ. sci. diss.]. Saint Petersburg, 2017. 431 p.

Barbashin M.Y. Imitation Modeling and Institutional Studies. Journal of Institutional Studies, 2017, vol. 9, no. 3, pp. 81-96. DOI: 10.17835/20766297.2017.9.3.081-096.

Kussy M.Yu., et al. Blockchain Technologies as a Stimulator of Institutional Transformations of the World Financial System. International Journal of Engineering and Technology (UAE), 2018, vol. 7, no. 3.14: Special Issue 14, pp. 354-359. DOI: https://doi.org/10.14419/ijet.v7i3.14.17025.

Bourdieu P. Le sens pratique. Paris, Minuit, 1980. 479 p.

Camerer C.F., Loewenstein G. Behavioral Economics: Past, Present, Future. Camerer C.F., Loewenstein G., Rabin M., eds. Advances in Behavioral Economics. Princeton, Princeton University Press, 2004, pp. 3-51.

Dopfer K., Foster J., Potts J. Micro-Meso-Macro. Journal of Evolutionary Economics, 2004, vol. 14, no. 3, pp. 263-279. DOI: 10.1007/s00191004-0193-0.

Elsner W. Why Meso? On "Aggregation" and "Emergence", and Why and How the Meso Level is Essential in Social Economics. Forum for Social Economics, 2007, vol. 36, no. 1, pp. 116. DOI: 10.1007/s12143-007-0001-3.

Freeman C., Perez C. Structural Crises of Adjustment: Business Cycles and Investment Behaviour. Dosi G., et al., eds. Technical Change and Economic Theory. London, New York, Pinter Publishers, 1988, pp. 38-66.

Furstenberg G.M. von. Acting Under Uncertainty: Multidisciplinary Conceptions. Bloomington, Springer-Science+Business Media, B.V., 1990.532 p.

Giddens A. The Constitution of Society. Outline of the Theory of Structuration. Cambridge, Polity Press, Oxford, Basil Blackwell, 1984. 402 p. 
Haken H. Information and Self Organization: $A$ Macroscopic Approach to Complex Systems. Berlin, New York, Springer-Verlag, 1988. 196 p. DOI: https://link.springer.com/book/10.1007\% 2F3-540-33023-2.

Hayek F.A. The Sensory Order: An Inquiry into the Foundations of Theoretical Psychology. Chicago, University of Chicago Press, 1999.232 p. DOI: $10.7208 /$ chicago/9780226321301.001.0001.

Holland S. The Market Economy. From Micro to Mesoeconomics. London, Weidenfeld and Nicholson, 1987. $370 \mathrm{p}$.

Knight J. Institutions and Social Conflict. Cambridge, Cambridge University Press, 1992. 234 + XIII p. DOI: $10.1017 /$ CBO9780511528170.

Kruglova M.S., Volynskii A.I., Kirilyuk I.L. Meso-Level of Economy: Theoretical Approaches and Math Modeling. Journal of Institutional Studies, 2019, vol. 11, no. 1, pp. 41-54. DOI: 10.17835/20766297.2019.11.1.041-054.

Miller G.M. Managerial Dilemmas: Political Leadership in Hierarchies. Cook K., Levi M., eds. The Limits of Rationality. Chicago, University of Chicago Press, 1990, pp. 343-344.

$\mathrm{Ng}$, Yew-Kwang. Mesoeconomics. A Micro-Macro Analysis. Brighton, Wheatsheaf Books, 1986. 267 p. DOI: $10.2307 / 2233193$.
Ostrom E. Governing the Commons: The Evolution of Institutions for Collective Action. Cambridge, Cambridge University Press, 1990.280 p.

Ozawa T. Organizational Efficiency and Structural Change: A Meso-Level Analysis. Boyd G., Dunning H.J., eds. Structural Change and Cooperation in the Global Economy. Cheltenham, Northampton, Edward Elgar, 1999, pp. 160-190.

Pagano U. Property Rights, Asset Specificity and the Division of Labor Under Alternative Capitalist Relations. Cambridge Journal of Economics, 1991, vol. 15, no. 3, pp. 315-342.

Tarasov V., Tarasova V. Economic Growth Model with Constant Pace and Dynamic Memory. Entropy, 2017 , no. 2 (84), pp. 40-45. DOI: $10.20861 / 2304-$ 2338-2017-84-001.

Vittikh V.A. Introduction to the Theory of Intersubjective Management. Group Decision and Negotiation, 2015a, vol. 24, iss. 1, pp. 6795. DOI: 10.1007/s10726-014-9380-z.

Vittikh V.A. Heterogeneous Actor and Everyday Life as Key Concepts of Evergetics. Group Decision and Negotiation, 2015b, vol. 24, iss. 6, pp. 949956. DOI: 10.1007/s10726-014-9423-5.

Voigt S. How (Not) to Measure Institutions. Journal of Institutional Economics, 2013, no. 9, pp. 1-26. DOI: $10.1017 / \mathrm{S} 1744137412000148$.

\section{Information About the Authors}

Mikhail Yu. Kussy, Candidate of Sciences (Economics), Associate Professor, Department of Agro-Industrial Complex Economy, V.I. Vernadsky Crimean Federal University, Prosp. Vernadskogo, 4, 295007 Simferopol, Russian Federation, mikhailkussy@gmail.com, https://orcid.org/0000-0001-5338-5600

Oleg L. Korolyov, Candidate of Sciences (Economics), Associate Professor, Department of Business Informatics and Mathematical Modeling, V.I. Vernadsky Crimean Federal University, Prosp. Vernadskogo, 4, 295007 Simferopol, Russian Federation, alekking@gmail.com, https://orcid.org/0000-0002-8059-7702

\section{Информация об авторах}

Михаил Юрьевич Куссый, кандидат экономических наук, доцент кафедры экономики АПК, Крымский федеральный университет им. В.И. Вернадского, просп. Вернадского, 4, 295007 г. Симферополь, Российская Федерация, mikhailkussy@gmail.com, https://orcid.org/0000-0001-5338-5600

Олег Леонидович Королев, кандидат экономических наук, доцент кафедры бизнес-информатики и математического моделирования, Крымский федеральный университет им. В.И. Вернадского, просп. Вернадского, 4, 295007 г. Симферополь, Российская Федерация, alekking@gmail.com, https://orcid.org/0000-0002-8059-7702 